\title{
Diagnostics of analog systems using Artificial Neural Networks
}

\author{
Piotr Bilski
}

Politechnika Warszawska, Wydział Elektroniki i Technik Informacyjnych, ul. Nowowiejska 15/19 (Gmach Elektroniki), 00-665 Warszawa

\begin{abstract}
The paper presents the diagnostic applications of artificial neural networks (ANN). Aims and problems present in the contemporary diagnostics are introduced. The structure of the artificial intelligence-based system is presented and discussed in detail. Various approaches to design the on-line fault detection and location system using artificial intelligence approaches are introduced. The generic architecture of the ANN and its variations are presented. Next, their diagnostic applications, advantages and drawbacks are discussed. Application of RBF ANN-based diagnostic module to detect and identify faults of the 5th order lowpass filter is presented. Finally, usability and limitations of the ANN-based diagnostic system are provided.
\end{abstract} Keywords: artificial intelligence, artificial neural networks, fault detection, analog systems diagnostics

\section{Introduction}

Diagnostics of analog systems is currently a wide domain with numerous applications, closely related to the types of analyzed objects. With the increasing number of such systems (including mechanical and electronic elements), the set of usable approaches also increases. Contrary to the digital object, its analog counterpart is characterized by the continuous transmission and processing of information. Therefore the system may also be in the infinite number of states, generating continuous signals. This makes the diagnostics of analog systems especially difficult. The most popular approaches used in the domain belong to Artificial Intelligence (AI). Their advantages include the autonomous operation (without the input of the human operator), high accuracy with generalization abilities and (in most cases) the ability to update knowledge through the additional learning procedure. Disadvantages include the dependency of the acquired diagnostic knowledge on the available data (use cases) presented during the training of the diagnostic module. Sometimes explanation of the reasoning process (i.e. how the premises were used to draw conclusions) is required. The most popular diagnostic methods, exploited in practice, are Artificial Neural Networks (ANN) [1, 2]. This paper presents the taxonomy, structural and operational details of ANN used for the diagnostic purposes. The structure of the paper is as follows. Section 2 presents diagnostic principles important from the AI-application point of view. In Section 3

Autor korespondujący:

Piotr Bilski, pbilski@ire.pw.edu.pl

Artykuł recenzowany

nadesłany 12.08.2017 r., przyjęty do druku 05.10.2017 r the generic diagnostic architecture is introduced with the focus on internal modules. Section 4 covers the ANN work regime from the diagnostic point of view. In Section 5 the main architectures of ANN with their applications are presented. Section 6 presents diagnostics of the $5^{\text {th }}$ order lowpass filter using the RBF ANN-based classifier. In Section 7 summary and future prospects of the discussed ANN are provided.

\section{Aims of the diagnostics}

Diagnostics is aimed at determining the actual state of the analyzed System Under Test - SUT, based on the observations of the measured signals $\boldsymbol{y}(t)$ being responses to the known excitation $\boldsymbol{x}(t)$. Similarly to the medical and veterinary diagnostics, in technical sciences non-invasive approaches are preferred, where the information about the system's behavior is available only through the input and output (accessible and partially accessible) nodes (with the maximum set of nodes being hidden, i.e. inaccessible). Therefore the diagnostic system is expected to establish relations (in the form of the unknown function $f()$ ) between the observable features of output signals and configuration of parameters $\boldsymbol{p}$ defining the SUT's work regime [1]. The latter can be based on the human expert's experience or the mathematical description of the system. Alternatively, simulations of the SUT model may provide the information about how it works and how changes in parameters influence behavior of the whole object. Such heuristic models are currently an important source of knowledge about the operating system, used to create data sets for AI-based classifiers.

$$
y(t)=f[x(t), \boldsymbol{p}, t]
$$

As analog systems are widely exploited and belong to the multiple technical domains, it is difficult to propose one universal diagnostic solution for all of them. Criteria determining usage of specific approaches include, among others, the ability to apply excitation signals to the SUT input (impossible in closed 
loop systems, such as DC motor or industrial installation), character of measured responses (occupation of the frequency band or physical nature - acoustic, electrical, etc. - of the generated signal), or work regime, allowing (or not) for dismantling the system for repairs. In Figure 1 the example of the electronic lowpass $5^{\text {th }}$ order filter is presented. It contains 9 nodes, which, depending on the designer's choice may be made accessible or not. The excitation is put to the node No. 1 , while from the output node (No. 9) responses are measured. Ten elements (resistances and capacitances) determine the frequency characteristics (Fig. 2), therefore their values should be identified during the diagnostic procedure. Nominal values for the $10 \mathrm{kHz}$ cutoff frequency of all elements, are as follows: $\mathrm{R}_{1}=\mathrm{R}_{2}=\mathrm{R}_{3}=\mathrm{R}_{4}=\mathrm{R}_{5}=1 \mathrm{k} \Omega, \mathrm{C}_{1}=$ $16 \mathrm{nF}, \mathrm{C}_{2}=19 \mathrm{nF}, \mathrm{C}_{3}=13 \mathrm{nF}, \mathrm{C}_{4}=51 \mathrm{nF}$ and $\mathrm{C}_{5}=49 \mathrm{nF}$.

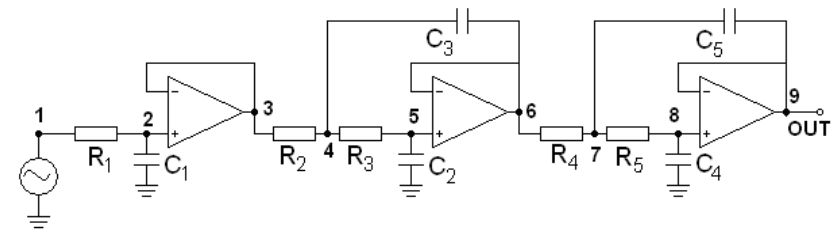

Fig. 1. Scheme of the 5-th order lowpass filter

Rys. 1. Schemat filtru dolnoprzepustowego 5. rzędu

According to (1), it is assumed that responses measured at accessible nodes are enough to determine the SUT state, which is not always true, as will be discussed later. From response signals characteristic features, which bear information about faults (further called symptoms) are extracted (see Fig. 3). Their form depends on the analyzed domain. For instance, in the time domain these can be positions of extreme values of the signal and the time instances of zero crossings. In the frequency domain spectral components at specific frequencies are used.

Depending on the expected diagnostic accuracy and application of the diagnostic process, the following detailed aims are exploited:

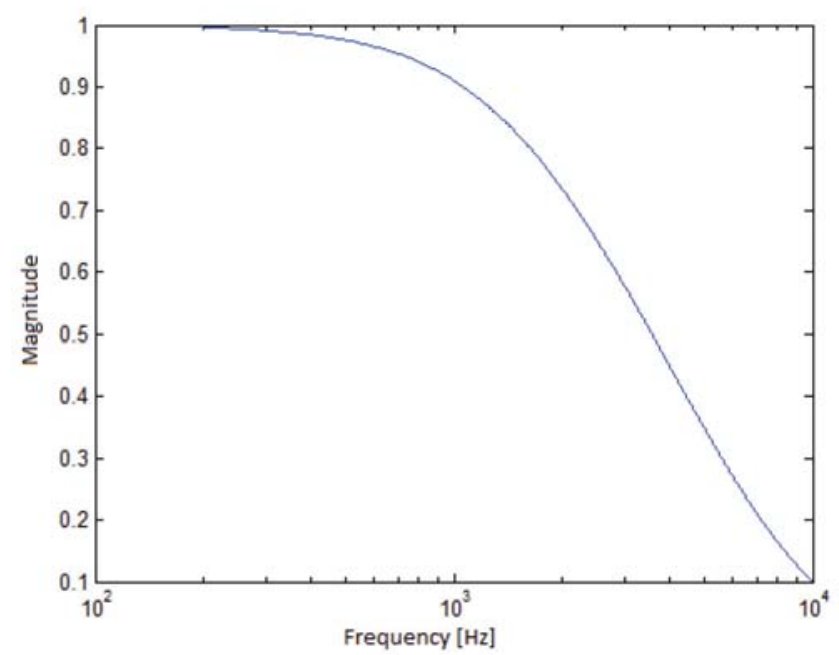

Fig. 2. Frequency characteristics of the 5-th order lowpass filter from Fig. 1

Rys. 2. Charakterystyka częstotliwościowa filtru dolnoprzepustowego 5. rzędu z Rys. 1

- fault detection, i.e. determining if the analyzed SUT is working correctly or not. This is the main aim in all production processes, where the newly created object must be checked if it meets the design requirements and can be sold. If the SUT is considered faulty, it is disposed of. In the case of on-line diagnostics of constantly working objects (such as motors, servomechanisms) or continuous processes, fault detection is the first step to the more detailed analysis.
- fault location is the process of determining, which parameter is beyond the tolerance margins and therefore the source of the fault. The aim is to determine the discrete number - the identifier of the parameter responsible for the incorrect behavior of the SUT. In the process diagnostics the term "fault isolation" is used. It is important during monitoring of large installations or machines that must operate constantly and can be turned off for repairs only for a short amount of time.

- fault identification is aimed at determining, what is the deviation of the faulty parameter from the designed value. This is the most detailed information especially useful in the diagnostics of systems, which cannot be easily opened and disassembled. It allows for compensating the parameter responsible for the fault with the additional signal (which is done in the feedback loops).

- fault prediction - based on the current measurement information obtained from the SUT, it is sometimes required to determine, how will the SUT behave in the nearest future. This aim requires determining trends and considering time and dynamics of changes. It is then used in large installations, such as power plants, but can also be applied to predict the life cycle of complex systems and devices.

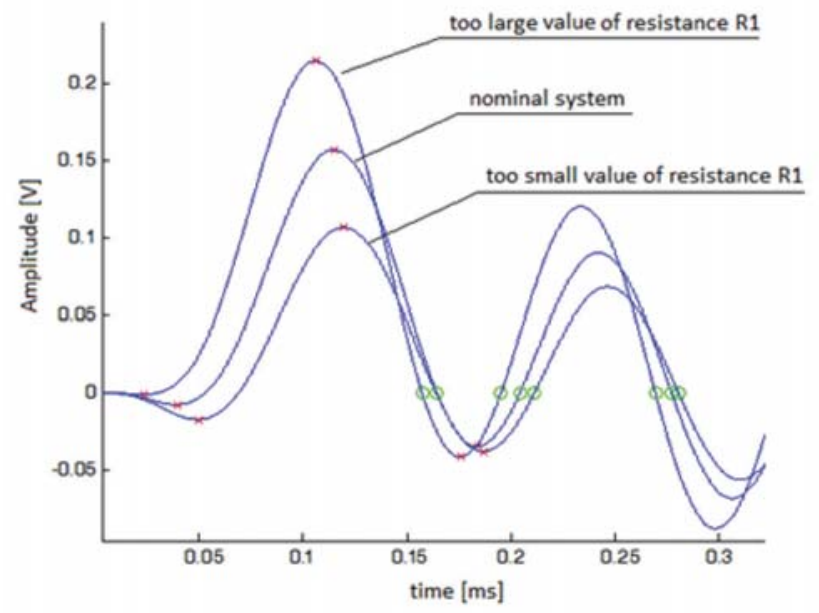

Fig. 3. Extraction of symptoms from the response of the electronic filter from Fig. 1

Rys. 3. Ilustracja pozyskiwania symptomów z odpowiedzi filtru elektronicznego z Rys. 1

All these aims refer to the nominal (compliant to the design specifications) and actual states of the SUT. In the system operating correctly both should be considered the same state. Determining whether the SUT is in the nominal state or distinguishing between various faulty states is usually difficult because of two factors:

- existence of the noise related to the operation of the SUT and the surrounding environment. The noise influences the measurement accuracy, degrading the fault detection and identification. In most cases, the noise is eliminated from the measured signals by de-noising.

- tolerances in the values of SUT parameters. They influence behavior of the system leading to changes in the symptoms' values, which may be misleading for the diagnostic system. Tolerances are the problem in the real systems (contrary to the computer models), as all constituent elements of the SUT are produced with the finite accuracy. Therefore each produced device or system is slightly different. It may be considered faulty if responses are beyond the predefined margins.

Both phenomena impose application of the diagnostic module operating in the uncertainty conditions (see Section 3). Reaching diagnostic aims is also impeded by Ambiguity Groups (AG), 
which are subsets of SUT parameters hardly distinguishable from each other [2]. Elimination of AG is done by increasing the number of accessible nodes or introducing additional symptoms, which allow for separating various faults.

The types of diagnosed faults are distinguished into parametric and catastrophic ones. The former refer to changes in the SUT parameters that do not modify its topology. Such faults are related with deviations slowly progressing in the SUT because of changing environmental conditions and wearing out its constituent elements. They can be used for determining the actual state of the system after the specified time of operation (to verify if it still meets the designer's assumptions). Such faults are more difficult to detect and identify especially because it is not easy to determine when the SUT goes out of the nominal state (while the process of changes is continuous). Identification and localization of parametric faults assumes the changes in the parameter are measurable based on output signals and their values proportional to the values of symptoms. Sometimes it does not hold, when the SUT's behavior has low sensitivity to the particular parameter. On the other hand, catastrophic faults (such as the short circuit in the electronic filter) change structure of the SUT, therefore abruptly influence its behavior. Such faults are easier to detect and identify.

Most diagnostic approaches (not only AI-based) exploit the SUT model simulation to confront it against the actual system. Two methods are used here: Simulation Before Test (SBT) and Simulation After Test (SAT) [3]. The first one relies on the extensive exploitation of the model to find dependencies between its internal structure and observable behavior. This is the widely used methodology for all data-driven methods, including the ones using AI. The SAT paradigm uses the SUT model in parallel with the actual system measurement. The residual information is the difference between the simulated and measured symptoms. This scheme is more challenging, as it introduces time limitations for making the decision. The on-line simulation is used in the monitoring systems of large and complex objects, such as nuclear power plants $[4,5]$. In this case, ANN are attractive, as they are fast and provide the acceptable accuracy. The ANN presented in this paper are in most cases (with exceptions presented in Section 4) used in the SBT methodology.

\section{Diagnostic architecture}

The general scheme of the diagnostic system is presented in Fig. 4, usually implemented as the combination of software and hardware modules. We assumed here the ability to select excitation signals, adjusted to the specific SUT, which is not always possible (for instance, in electrical machines, or industrial installations). The most important part is the diagnostic algorithm, although its efficiency depends on the set of symptoms used for distinguishing between faults. The symptoms belong to one of the following domains: time (like the duration of the impulse), frequency (values of harmonic components) or mixed (like wavelet coefficients). Based on the set of symptoms $s=\left\{s_{1}, \ldots, s_{m}\right\}$ and knowledge about dependencies between them and values of parameters $\boldsymbol{p}=\left\{p_{1}, \ldots, p_{k}\right\}$, the diagnostic decision can be made. The source of knowledge may be human- or machine learning - originated. In both cases, the automated diagnostic system is treated as the expert system (Fig. 5), able to perform deductive process on the vector of actual data extracted from the monitored SUT. The automated knowledge extraction from the learning data set allows for creating the knowledge base. It is then used to make decision about the state of the SUT based on the vector of actual symptoms $s_{a}$. The additional explanation mechanism may be present to describe the deductive process to the human operator. It is used to check if the diagnostic system operates correctly. If needed, changes can be made to the reasoning mechanism. Implementation of the diagnostic system depends on the exploited AI algorithm. Despite multiple differences between the particular approaches, their advantages include the adaptation to the available data, autonomous operation and, in most cases, ability to extract knowledge from the training data sets. In each category there is usually at least one method tackling data measured in the uncertainty conditions.

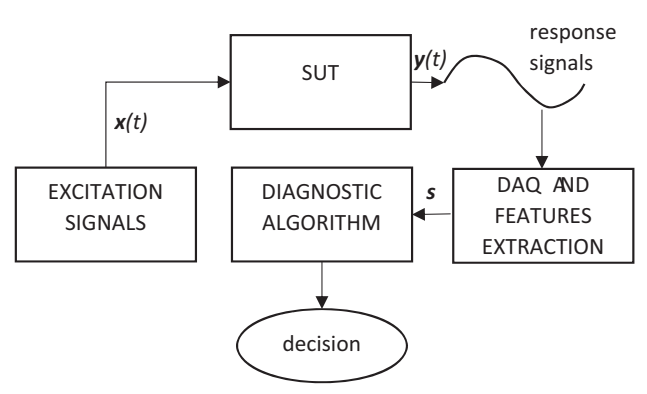

Fig. 4. Generic diagnostic architecture Rys. 4. Ogólna architektura diagnostyczna

The diagnostic procedure is implemented in off-line or on-line conditions. In the former, the SUT may be disconnected from the operating environment and then thoroughly tested. Regarding the moment of collecting knowledge by the diagnostic module, this operation uses the SBT scheme. In the on-line case (when the diagnosed system must be monitored during its normal operation), the SAT approach is applied.

AI is widely used in the diagnostics. Among multiple approaches the most popular are presented in Fig. 6. This taxonomy distinguishes the form of knowledge used during the reasoning process. The rule-based approaches exploit IF THEN structures, combining premises (i.e. conditions that must be met if the rule is to be activated or fired) with conclusions (in this case the diagnostic decision). This gives the legible form of the diagnostic process, which is true for Decision Trees (DT) or Rules Inference (RI) modules. Fuzzy Logic (FL) [6] is the most sophisticated method, operating in the uncertainty conditions, but is devoid of the machine learning algorithm. Therefore knowledge must be provided to the system by human or the additional method. Rough Sets (RS) operate on the similar principle as FL, but require the preceding discretization of symptoms' continuous values. Numerical approaches mainly cover the Artificial Neural Networks (ANN) and their versions (as will be presented in Sections 4 and 5). Statistical approaches are based on the Bayes theorem and allow for making decision based on the established a priori knowledge and observed a posteriori data. The simplest algorithm is the Naïve Bayes Classifier (NBC), although Bayesian Networks (BN), used mainly in the analysis of industrial systems [7] and Hidden Markov Models (HMM) [8] are applied as well. Finally, distance-based approaches make decision about the fault of the SUT by calculating the distance between the symptoms' vectors forming the dictionary (data set $\mathrm{L}$ containing $\mathrm{n}$ labeled vectors of $\mathrm{m}$ symptoms - see (2)) and the actual set of measured symptoms $\boldsymbol{s}_{\boldsymbol{a}}$.

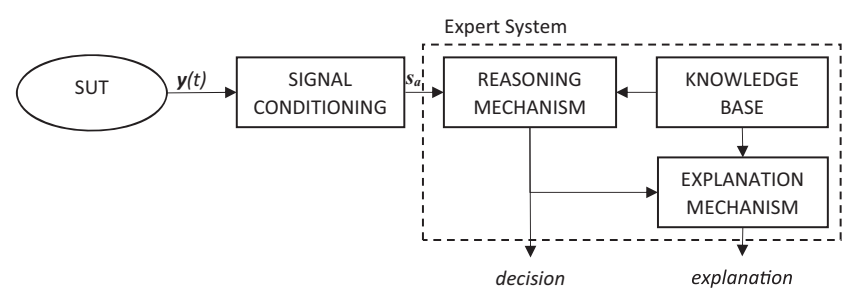

Fig. 5. Architecture of the Al-based diagnostic system Rys. 5. Architektura systemu diagnostycznego wykorzystującego sztuczną inteligencję 
The most popular method here is the $\mathrm{k}$ Nearest Neighbor $(\mathrm{kNN})$ classifier. Among all these methods ANN are the most popular because of their easy implementation (multiple software libraries exist for virtually all programming languages). They will be presented in detail.

$$
L=\left[\begin{array}{cccc}
s_{11} & \ldots & s_{1 m} & c_{1} \\
\vdots & \ddots & \vdots & \vdots \\
s_{n 1} & \ldots & s_{n m} & c_{l}
\end{array}\right]
$$

\section{Characteristics of ANN}

All ANN are structures containing neurons (or computational units) strongly interconnected with each other. They are able to perform complex computations using simple mathematical operations, such as multiplication and addition. Each neuron is represented by the activation function, producing the output value $o$ depending on $l$ input values $q_{i}[9]$.

$$
o=f(h)=f\left(\sum_{i=1}^{l} w_{i} \cdot q_{i}\right)
$$

Activation functions are usually continuous (with exception of Heavyside and signum functions). The simplest one is the linear function, where the output $o$ is just the result of multiplying the matrix $\mathrm{W}$ and the input vector $q(4)$. The sigmoidal functions produce continuous values, respectively, between 0 and 1 , and -1 and 1 . Another popular version is the Gaussian function, used in RBF networks.

$$
h=\left[\begin{array}{c}
h_{1} \\
\vdots \\
h_{k}
\end{array}\right]=W \cdot q=\left[\begin{array}{ccc}
w_{11} & \cdots & w_{1 l} \\
\vdots & \ddots & \vdots \\
w_{k 1} & \cdots & w_{k l}
\end{array}\right] \cdot\left[\begin{array}{c}
q_{1} \\
\vdots \\
q_{l}
\end{array}\right]
$$

Knowledge obtained during the ANN training has the form of the weights' matrices $W(4)$, representing connections between particular neurons. Values of weights are optimized during the training to adjust the ANN structure to the solved problem. According to (4), the ANN signal processing consists in the matrix multiplication, which makes such a system computationally efficient fast and feasible to the on-line diagnostics.

Because of the ability to learn and fast on-line operation, ANN are widely used in two main problems, which are also present in the diagnostics:
- Classification - the aim here is to determine (based on the values of selected symptoms) the discrete state of the SUT (represented by the category being usually the integer number). The binary classification (" 0 " or " 1 " category) is performed only to detect the fault, without the detailed analysis of its source. In the case of catastrophic faults, the multi-class categorization can be performed to determine the faulty element. In the case of parametric faults, the classification requires determining at least the identifier of the faulty element (for the location) and (in the case of the fault identification) its deviation degree from the nominal value. This is more complicated, requiring division of the continuous range of each parameter's changes into a number of intervals. In the most general configuration, each parameter or element is represented by two codes, determining its value being greater or lesser than the nominal one. To increase the diagnostic resolution, more discrete values to identify may be introduced, such as "much lesser than", "lesser than", "greater than" or "much greater than" the nominal value. This way fault codes, usable during the machine learning, can be prepared. For the purpose of AI methods, these values are used to create categories in the data sets (the last column in $L(2)$ ).

- Regression - the aim is to determine the actual values of the SUT parameters based on the values of symptoms. The operation consists in mapping the vector of features into one or more real-valued parameters.

The additional issue regarding the classification task in diagnostics is that multiple parameters may be the source of the fault. This requires application of specific algorithms able to point out multiple fault codes simultaneously. To achieve that in the ANN-based diagnostic system, the specific coding scheme must be used (see below). Majority of ANN are one-directional networks, where vector of symptoms enters the ANN-based diagnostic system (see Fig. 7). Its neurons are usually organized into layers, between which signals are transmitted, starting from inputs (where no actual calculation is performed), through a number of hidden layers, concluding with the output layer. This way the ANN can be seen as the "black box", because the direct relation between the set of symptoms provided to the input of the network and the diagnostic information, produced by the output layer is not known.

Most ANN configurations presented in Fig. 6 are used to perform classification and regression, although prediction is also tried. The number of neurons in hidden layers is the parameter of the network, optimized depending on the data provided during the training. Although there are algorithms of adjusting the number of layers and their neurons in the process, the typical

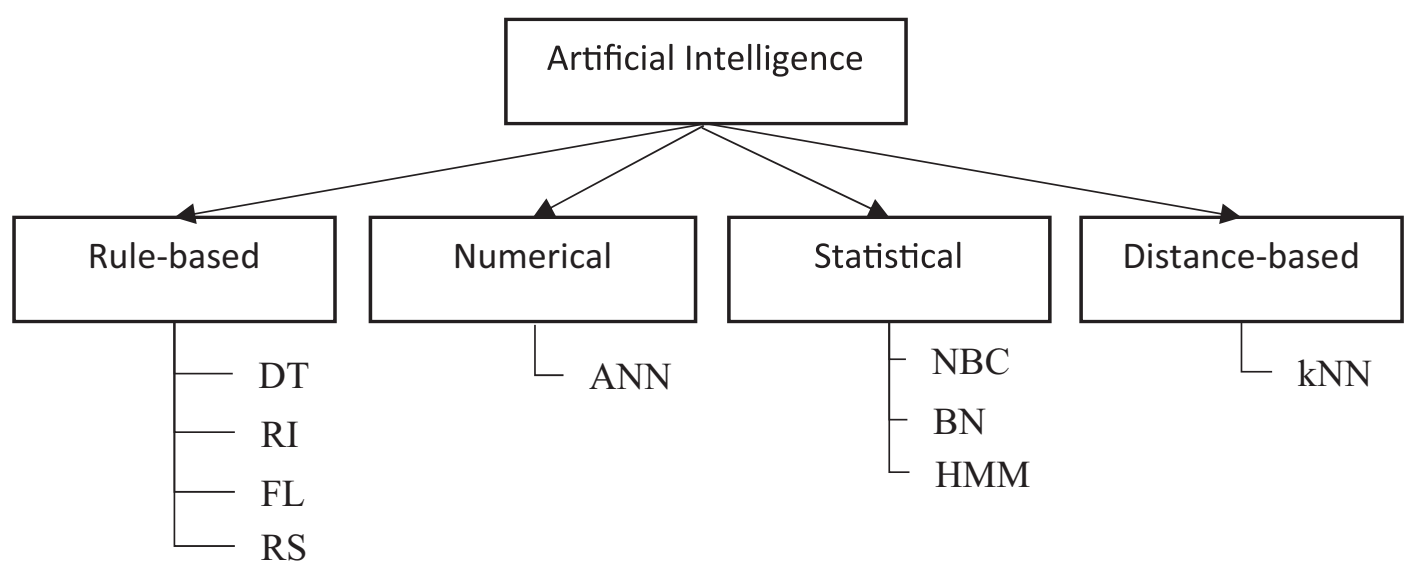

Fig. 6. Taxonomy of Al methods for the diagnostics of analog systems

Rys. 6. Klasyfikacja metod sztucznej inteligencji w diagnostyce systemów analogowych 


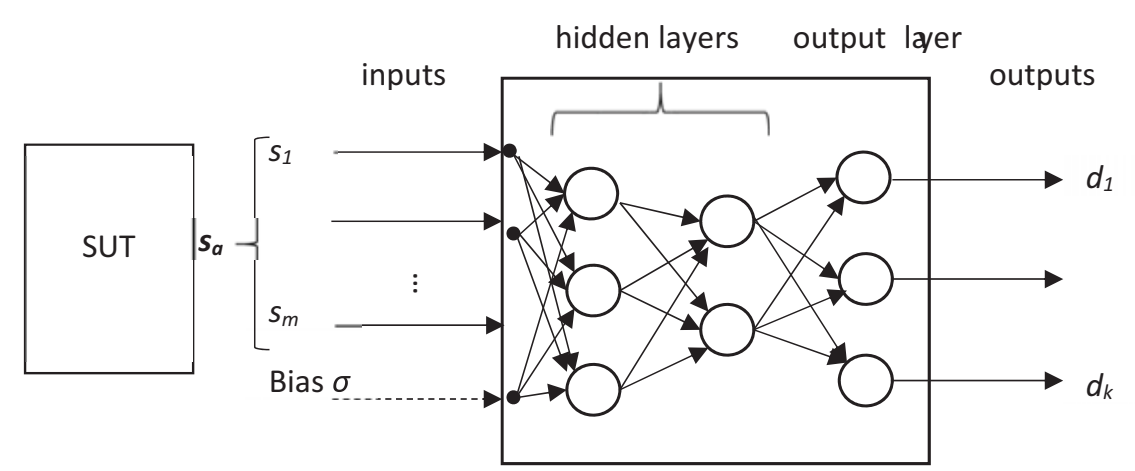

Fig. 7. Structure of the ANN-based diagnostic module

Rys. 7. Struktura modułu diagnostycznego wykorzystującego sztuczne sieci neuronowe

approach for the design of the optimal diagnostic system is to perform training on the same data set multiple times, for different number of neurons and layers. The type of applied hidden neurons (sigmoidal, Gaussian, etc.) depends on the particular architecture. The number of neurons in the output layer is adjusted to the solved task. In the regression, the number of neurons is the number of predicted parameters. The linear activation function is used here. In the classification task (fault detection, location and identification) the situation is more complex. The sole fault detection is the binary classification problem, therefore the single sigmoidal neuron is enough to do the job. In the multi-class problem (fault identification and location), there is the need to use multiple binary-valued neurons, which values form binary combinations attributed to the particular fault code. Various coding schemes are used, among which the most popular are One versus All (where each neuron represents the separate category) and Minimum Output Coding (where the combination of outputs forms the identifier). The former is simple and potentially allows for detecting multiple faults. The latter uses the minimum number of neurons. To minimize the probability of classification error, at the expense of additional neurons, the Error Correcting Output Coding may be used [1].

Another aspect of the ANN application in diagnostics is the training mode (see Fig. 8). Most structures are applied in the supervised learning, where the data analyzed to extract knowledge is labeled, i.e. the relation between the set of symptoms and the specific SUT state is known and written into the set, of the form like (2). In some cases such an information is not known and the aim of learning is to determine the relations within data.

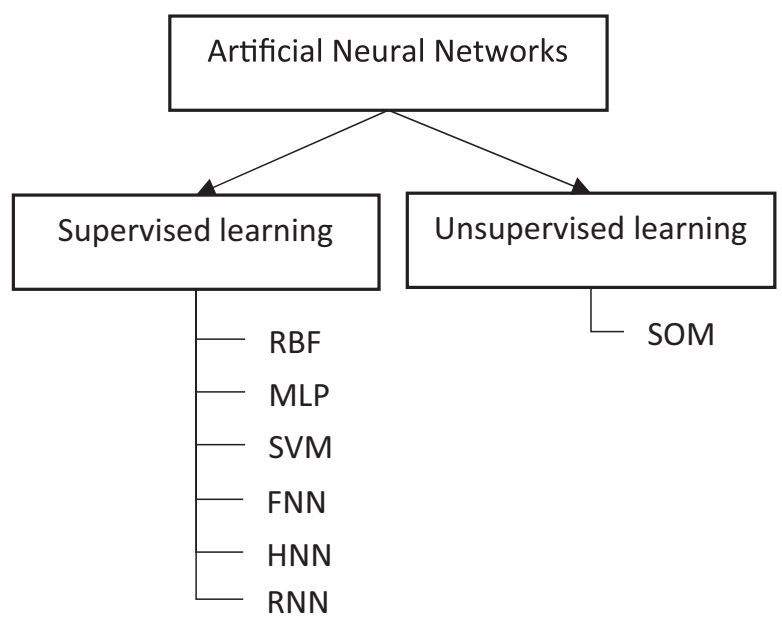

Fig. 8. Taxonomy of the ANN used in diagnostics Rys. 8. Klasyfikacja sztucznych sieci neuronowych wykorzystywanych w diagnostyce
The most popular is supervised learning, where each example in the training set is labeled, i.e. the category of each vector of symptoms is known. In the diagnostics of industrial processes the relation between symptoms and the fault is rarely known, which makes this type of learning not applicable.

In the unsupervised learning no labels of examples are given, so the task for the network is to find dependencies in data (in the form of clusters of similar vectors of symptoms). The base for the process is the set $L(2)$ without the last column. This way fault categories may be created during the training and next used to determine the state of the actual SUT.

\section{Diagnostic applications of ANN}

This section introduces the particular ANN configurations and their diagnostic applications. Each network type is presented, its advantages and drawbacks discussed in detail. All abbreviations refer to the taxonomy of Fig. 8.

- Multilayered Perceptrons (MLP) - these are the oldest and the best established networks, used to solve various problems in biological, environmental and technical domains. These are the most general architectures, with potentially multiple hidden layers. The widely used efficient training method of MLP includes the Levenberg-Marquardt algorithm. The MLP were mainly used in fault detection and fault location tasks [10]. They were also implemented in hardware, such as digital signal processor or FPGA [11]. Their typical diagnostic applications include the fault detection in industrial processes, where the failures of particular elements of the system (such as the actuator or the sensors) are monitored [12]. Other applications include classification of faults in the automotive engine [13] based on the vibration signals. Obtained results show the MLP is comparable to the Kalman Filter, often used as the SAT approach in the on-line diagnostics. In [14] the MLP was used to detect catastrophic faults in the measurement instruments being the part of the more complex system. The number of hidden layers in the applied networks is no greater than two.

- Radial Basis Function (RBF) networks - are mainly used in the parameter identification (i.e. regression task) [15], although the classification was tried as well [16]. The RBF architecture contains the single layer with Gaussian activation function and the linear functions in the output layer. RBFs are considered as equally accurate to MLP with the simpler training algorithms. On the other hand, training requires larger data sets, which can be suppressed, using, for instance, correlation method [17].

- Support Vector Machines (SVM) - because analysis of actual SUTs considers uncertainty conditions, methods able to tackle this problem were introduced. The most popular is the 
advanced type of ANN, which, through the quadratic programming, positions the hyperplane separating vectors of symptoms belonging to different categories so that the error is minimal, SVM are widely used for both fault identification and regression tasks. The structure of the single SVM, processing $m$ symptoms and producing one output value is presented in Fig. 9. The key operation is the transformation from the original space of features into the optimal one, where various SUT states are easier distinguishable. This is done using the parameterized kernel function $K$ (equivalent of the activation function in the traditional networks). The most popular kernels are linear, polynomial and RBF, although many other can be used [18]. In the case of classification, coding schemes are the same as for other networks. The SVM provide optimal classification and regression results when environmental noise or tolerances of elements are employed. Their disadvantages include a long and complex optimization process, involving selection of the most suitable kernel and its parameters. Applications of SVM are wide, starting from the analysis of analog circuits [19], through the electrical machines [20], up to industrial installations [21]. During the SVM-based diagnostic system the most important problem is selection of the best values of kernel parameters. Among many approaches tried there are genetic algorithm or simulated annealing [22].

- Fuzzy Neural Networks (FNN) - this is another structure, allowing for operation in the uncertainty conditions. This network is a combination of FL inference system with the training algorithm typical for the ANN. This way five layers are created, each responsible for a single operation in the FL module. The structure of the typical FNN is in Fig. 10.

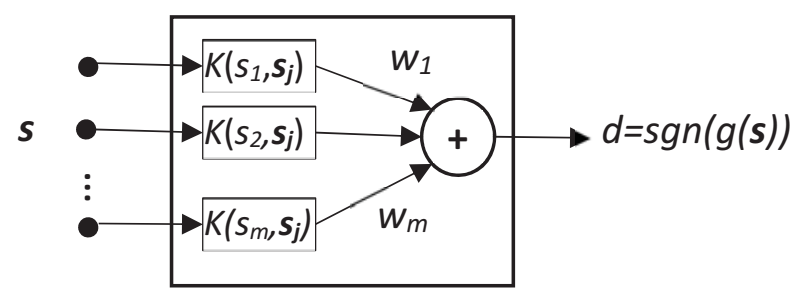

Fig. 9. Structure of the binary SVM classifier Rys. 9. Struktura binarnego klasyfikatora SVM
The network operates by activating fuzzy rules, which are used to produce output values. Applications of FNN are similar to SVM, where the diagnosed objects are automotive or electrical motors [23], as well as industrial installations [24].

- Self-Organizing Maps (SOM) - this is the most popular unsupervised learning network, which is trained to create categories (forming groups of similar vectors of symptoms) representing SUT states. The network is one-layered (see Fig. 11), where all neurons are positioned on the plane. During the machine learning, the neurons with weights the most similar to the currently presented vector of symptoms (in the sense of selected distance, such as Euclidean) are trained to react even stronger to these vectors. In the end of training, the neurons reacting to any sets of symptoms are treated as the centers of clusters and represent categories. SOM can be used for the fault identification, but also detect ambiguity groups [25]. Recently, such networks were used in the hierarchical diagnostics system as the introductory classifier [26].

- Recurrent Neural Networks (RNN) - these networks are used in the model-based diagnostics. In their structure the feedback loops are present. Templates representing various SUT states are first inserted into the weight matrix and in the process of switching states the network ends up in the steady state. This way the final diagnostic decision is made. Such networks are used as the SAT approaches to diagnose industrial processes (elements of sugar factory [27]). Other architectures include the application of structures similar to MLP, but with the feedback loops inserted. Such networks are used to solve similar problems as more traditional approaches, like the analysis of induction motor [28] or power electronics elements [29].

- Hierarchical Neural Network (HMM) - this is the more complex structure [30] exploiting ANN architectures presented above. Usually multiple networks are used here, trained on various data sets and for different purposes. For instance, one top-level network is trained to detect faults, while networks at the lower level are responsible for isolating specific faults. In such architectures the ANN is often combined with other approaches, responsible for the detailed fault identification. For example, logical inference mechanism was used in the second stage of the power transmission system diagnostic module [31]. Such approaches allow for identifying multiple faults in large scale systems.

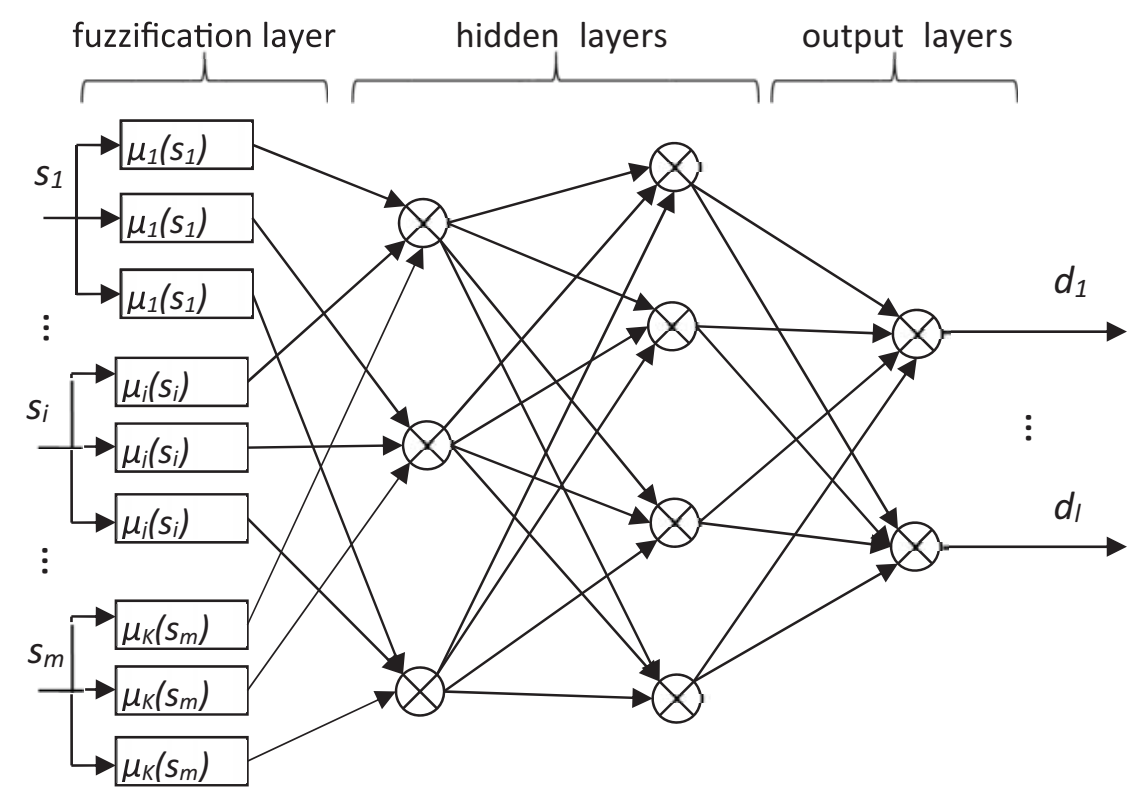

Fig. 10. Hybrid structure of the FNN

Rys. 10. Struktura hybrydowa rozmytej sieci neuronowej 


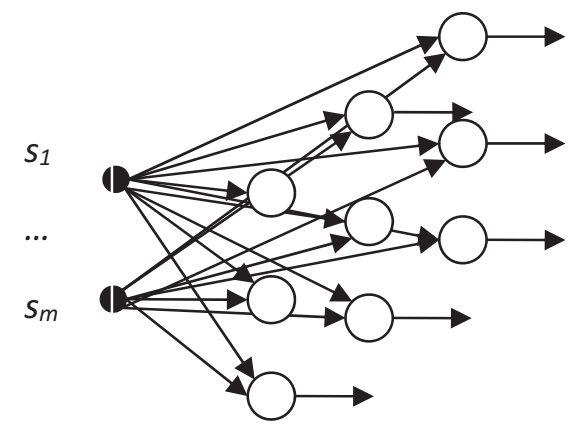

$d_{i}$

Fig. 11. Structure of the Self-Organizing Map

Rys. 11. Struktura mapy samoorganizującej się

The important issue is the correct selection of symptoms extracted from measured signals. Their set depends on the particular SUT and domain of analysis (for instance, in the acoustic analysis, cepstral components of the recorded sound are often used). If collected values are not enough to make all faults distinguishable, the additional method can be introduced to preprocess the data, such as transforming it into the new feature space, where the task would be easier. Although SVM have this feature inherent, in other architectures, such as MLP or RBF the external method is added, like Principal Component Analysis (PCA) or Independent Component Analysis (ICA) [32].

To maximize the accuracy of the diagnostic system, the optimization procedure is often employed. Its task may be to adjust the neurons and weights between them to the training data as the alternative to the traditional learning algorithms [16]. Also, the discrete optimization method can be used to adjust the ANN structure (number of neurons in hidden layers), while the continuous optimization is used to set parameters of the activation functions or kernels, which is done before each training process.

\section{Experimental example}

This section presents the numerical example of the diagnostic system presented in Fig. 7, based on the supervised learning RBF network (i.e. containing the single hidden layer with Gaussian activation function neurons). Contrary to its usual application (i.e. the regression), here this network was used for the classification. This is the part of work presented in [17]. The model of the lowpass filter from Fig. 1 was simulated in the Simulink environment, allowing for producing examples for sets $L$ and $T$. The diagnostic procedure is performed in the off-line mode (after isolating the SUT from the operating environment). Simulations consisted in putting the excitation sinusoid ( $1 \mathrm{~V}$ amplitude and $9 \mathrm{kHz}$ frequency) to the node No. 1 and recording responses on the output node (No. 9), and all other made accessible during the circuit design. Note that during the model simulation there is the full freedom of selecting the set of available nodes. In the real world the consequences of this operation are additional pins in the casing of the integrated circuit, making the design more complex and expensive.

To create the single example (set of symptoms) from the simulation, the selected SUT parameter was first changed to represent the single parametric fault. Values of other parameters maintained nominal. To incorporate the influence of tolerances on actual elements, each parameter was changed randomly (with the normal distribution) to have deviations within 10 percent of the original value. The range of parameter changes was $80 \%$ of the nominal values, leading to examples representing the SUT behavior for values smaller and larger than the nominal one. The SUT was analyzed in the time domain, therefore from each output sinusoid, the first three extreme values and zero crossings with their time instants were acquired (as in Fig. 4). This way at each node nine features are collected. Depending on the number of accessible nodes, the cardinality of the set of symptoms varied from 9 (only the output node) to 54 (nodes 2, 4, 5, 7, 8, 9 made accessible). All examples were supplemented with fault codes, i.e. discrete values representing the source of the fault and its intensity. The code [1] consists of the number of the faulty element (subsequent resistances were assigned numbers from 1 to 5 , while capacitances - from 6 to 10). The deviation from the nominal value is represented by one of four integers: $-2,-1,1$ and 2 , standing for "much smaller than", "smaller than", "larger than" and "much larger than" the nominal state. This way the code -21 means that the second resistor has the value smaller than the nominal value, while 72 is for the second capacitor with the value much larger than the nominal one. The fault-free state (when all SUT parameters are within tolerance margins, i.e. different than nominal values at no more than $10 \%$ ) is represented by the code 0 . The thresholds separating subsequent deviation levels of the parameter $p_{i}$ were set at $50 \%$ and $10 \%$ of the nominal value $p_{n i}$, as in Fig. 12. This gives 41 fault codes to distinguish for the ANN-based classifier. Each SUT element was deviated the same number of times, which led to the sets with size of 70 and 180 examples, depending on the number of simulations ( 7 or 18 for each parameter). Examples for the testing set were acquired the same way, but for different values of parameters. This allows for testing the generalization capabilities of the diagnostic system. Two sizes of data sets were prepared. In the first case, 7 examples were acquired for each parameter, leading to set size of 70 examples. In the latter case, 18 parameter values were simulated, leading to 180 examples in the set. In the presented experiments both sets will be referred to as $L_{1}$ and $L_{2}$ (while the testing sets are labeled as $T_{1}$ and $T_{2}$, respectively).

The diagnostic accuracy in the presented case is defined as the relative number of correctly classified examples from the set $T$ :

$$
a c c=\frac{|s: c(s)=d(s)|}{|T|}
$$

The presented experiments were aimed at establishing the following goals (especially important for the architecture of the RBF network):

- Determining the influence of the training set size on the fault identification accuracy.

- Comparing various output layer coding schemes on the identification accuracy.

- Selecting the optimal set of accessible nodes ensuring the acceptable diagnostic accuracy.

Three coding schemes in the output layer were used for experiments: One versus All, Minimum Output Coding and One versus One, determining the number of neurons in the output layer $o$.

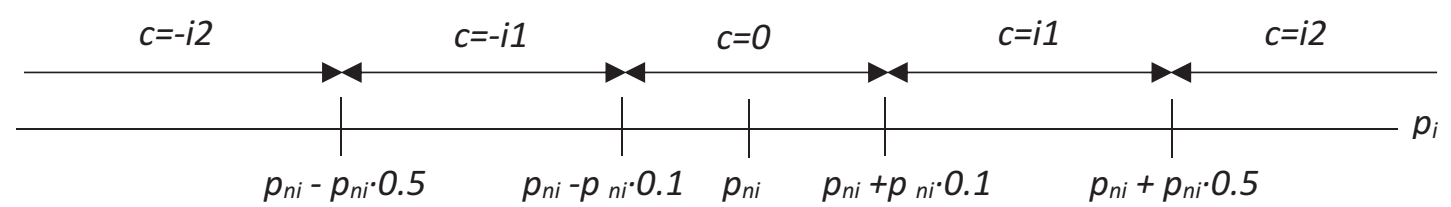

Fig. 12. Assignment of the fault code regarding the deviation of the parameter from the nominal value

Rys. 12. Przydział kodu uszkodzenia na podstawie odchylenia wartości parametru od nominalnej 
In the first case 41 categories had to be distinguished (one neuron for each fault category), the second one required 6 neurons (as they are able to encode up to 64 categories), while the OvO scheme required to train 820 networks, each with the single output responsible for distinguishing between two categories. Parameters of networks during their training included the optimal number of hidden neurons $k$, width of the Gaussian function $\sigma$ and target error $e$ during the training. The RBF network was implemented using the MATLAB Neural Networks toolbox.

Table 1 presents the accuracy of the diagnostic module for the larger set $T_{2}$ (with 180 examples) using three coding schemes. The experiments were conducted on six available nodes, i.e. 2, 4, 5, 7, 8 and 9. The OvO coding is the most effective, despite its most complex structure, requiring multiple (though relatively simple) networks. On the other hand, their hidden layers contain the smallest number of neurons (the average is 8). The latter was determined by repeating the training procedure for the increasing number of neurons. After initial increase of the diagnostic accuracy, the further addition of neurons does not improve the network performance. Therefore the minimum number ensuring the maximum accuracy should be selected. This method requires repeating the training-testing scheme many times and therefore is time-consuming. Alternative approaches consist in optimizing the number of neurons using sensitivity approaches [33]. The training error $e$ in all cases should be close to zero, ensuring the proper adjustment to available data.

Table 1. Diagnostic accuracy for various RBF network coding schemes

Tabela 1. Dokładność diagnostyki dla różnych schematów kodowania w sieci typu RBF

\begin{tabular}{|c|c|c|c|c|c|}
\hline Coding scheme & $\sigma$ & $k$ & $o$ & $e$ & acc [\%] \\
\hline OvA & 0.5 & 82 & 41 & 0.0 & 81.11 \\
\hline OvO & 0.6 & 8 & 820 & 0.0 & 83.33 \\
\hline MOC & 0.3 & 95 & 6 & 0.02 & 80.56 \\
\hline
\end{tabular}

In Figure 13 dependency between the diagnostic accuracy and the size of the training set is presented. As RBF networks are susceptible to the amount of training data, it is important to determine, what is the minimal amount of information required to extract significant diagnostic knowledge. Results in Table 2 show accuracy of the optimal networks, trained on the available sets. The set $L_{1}$ clearly contains not enough data that would allow for the proper generalization. Only larger sets can be used to obtain the acceptable accuracy. Note that it is unknown, which examples ensure the proper accuracy, therefore the size of the set is of the secondary importance. To determine this parameter, the additional analysis of examples must be performed (for example, exploiting the informativeness criterion [34]).

Table 2 presents the analysis of the diagnostic accuracy depending on the set of accessible nodes for the OvA coding. Initially, only responses at the node No. 9 are recorded (which is the typical for the real system). It is only sufficient to detect the fault but not enough to determine changes in all parameters. To achieve this goal, more nodes have to be added to the analysis. Because they are located in the filter one after another, experiments consisted in adding data from them in the specified order. The greatest increase in the information about faults is expected to be obtained after adding nodes in the middle and closer to the output. Therefore the following sequence was proposed: $9,5,8,7,4$. For the comparison purposes, results for the analysis of selected single internal nodes were added to illustrate the amount of information obtained from subsequent parts of the circuit. Optimal values of the RBF width $\sigma$ and the number of

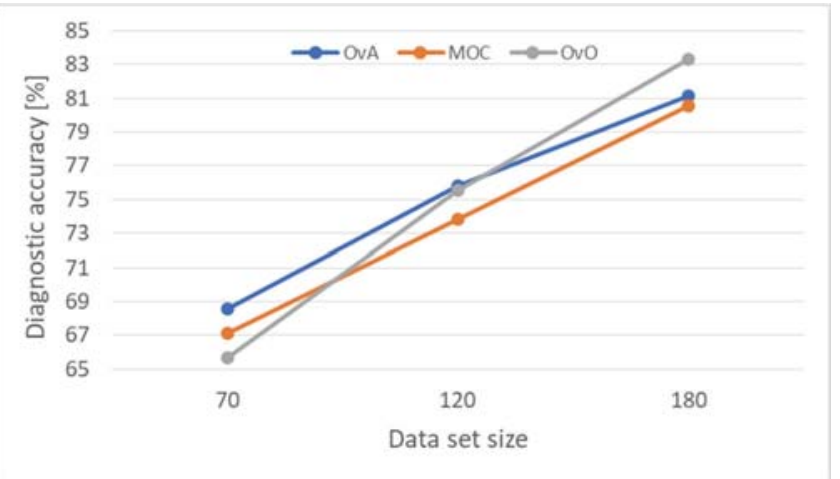

Fig. 13. Diagnostic accuracy of the RBF ANN-based classifier depending on the training data set size

Rys. 13. Dokładność diagnostyki klasyfikatora wykorzystującego sieć RBF w zależności od rozmiaru zbioru danych

neurons in the hidden layer $k$ are given as well. Addition of nodes closer to the output of the circuit increases the accuracy until no significant improvement can be obtained. This leads to the set of nodes important from the diagnostic point of view, while all others don't have to be accessible. Note that similar analysis must be performed for every circuit separately. For larger circuits, automated node selection methods are proposed [35].

Table 2. Diagnostic accuracy of the RBF ANN-based classifier (OvA coding) depending on the set of accessible nodes

Tabela 2. Dokładność diagnostyki klasyfikatora wykorzystującego sieć RBF (schemat kodowania OvA), w zależności od zbioru węzłów dostępnych

\begin{tabular}{|c|c|c|c|}
\hline Analyzed nodes & $\sigma$ & $k$ & acc $[\%]$ \\
\hline 5 & 0.3 & 68 & 39.55 \\
\hline 8 & 0.1 & 136 & 51.22 \\
\hline 9 & 0.1 & 161 & 38.99 \\
\hline 9,5 & 0.3 & 78 & 60.66 \\
\hline $9,5,8$ & 0.2 & 100 & 76.66 \\
\hline $9,5,8,7$ & 0.2 & 92 & 77.33 \\
\hline $9,5,8,7,4$ & 0.5 & 104 & 77.33 \\
\hline $9,5,8,7,4,2$ & 0.5 & 104 & 81.11 \\
\hline
\end{tabular}

The presented experiments show usefulness of the RBF network as the parametric fault classifier. Its accuracy depends on the quality of the available data, which depends on:

- the number of examples, representing behavior of the SUT

for different values of parameters,

- the number of accessible nodes (determining its testability), - domains of analysis (selected according to the SUT work regime).

Although the optimization process, i.e. adjustment of the network structure to the available data is time consuming and complex, it is performed in the SBT mode, therefore its duration is of secondary importance. The actual classification procedure is fast even for the most complex OvO scheme. To have idea of the proper network structure prior to the training, the data set processing (such as the correlation analysis) should first be performed. Also, comparison between different variants of the ANN-based diagnostic modules should be made. Currently, there are multiple alternative configurations usable for the diagnostic task, such as the RBF network, MLP or SVM. Selection of the best network may depend on the analyzed case. 


\section{Summary}

Multiple applications of the neural networks to the diagnostic domain are related to their wide software and hardware implementations and versatility, making them usable in most contemporary problems. Diagnostics of analog systems often uses various architectures, depending on the particular aim, and specific conditions (like separability of faults based on the available set of symptoms). Although knowledge stored in the ANN structure is illegible for the human expert, ANN are a handy tool, which (after sometimes time consuming optimization) provide high accuracy. The duration of operation is short enough to make them usable in the on-line mode.

Future implementations and development of ANN should cover simplification of architectures with the increase of the generalization ability. Such effects as tolerance of elements or environmental noise require more sophisticated approaches, like RNN or SVM. Hierarchical approaches, although seemingly more complex, may include simple structures of classification/regression machines. This leads to the overall simple and fast diagnostic module. Also, combination of ANN with other AI-based methods should be investigated. Such solutions may be required to solve problems still existing in the domain, such as isolation of multiple faults at the same time [36] or accurate diagnostics of complex systems [1,37].

\section{References}

1. Bilski P., Artificial intelligence methods in the diagnostics of analog systems, Oficyna Wydawnicza Politechniki Warszawskiej, Warszawa 2013.

2. Stenbakken G.N., Souders T.M., Stewart G.W., Ambiguity groups and testability, IEEE Trans. Instr. and Meas., Vol. 38, Iss. 5, 1989, 941-947.

3. Grzechca D., Golonek T., Rutkowski J., Analog Fault AC Dictionary Creation - The Fuzzy Set Approach, Proc. ISCAS 2006, 5744-5747.

4. Santhosh P.M., Kumar M., Thangamani I., Mukhopadhyay D., Verma V., Rao V.V.S.S., Vaze K.K., Ghosh A.K., Neural network based diagnostic system for accident management in nuclear power plants, Proc. 2nd International Conference on Reliability, Safety and Hazard (ICRESH), Mumbai, India, 14-16 Dec. 2010, DOI: 10.1109/ICRESH.2010.5779613.

5. Kim K., Bartlett E.B., Nuclear power plant fault diagnosis using neural networks with error estimation by series association, IEEE Trans. on Nuclear Science, 1996, Vol. 43, No. 4, 2373-2388, DOI: 10.1109/23.531786.

6. Kulkarni M., Abou S.C., Stachowicz M., Fault Detection in Hydraulic System Using Fuzzy Logic, Proc. World Congress on Engineering and Computer Science (WCECS) 2009, Oct. 20-22, San Francisco, USA.

7. Garza Castanon L.E., Nieto Gonzalez J.P., Garza Castanon M.A., Morales-Menendez R., Fault Diagnosis of Industrial Systems with Bayesian Networks and Neural Networks, "LNCS", MICAI 2008: Advances in Artificial Intelligence, Oct. 27-31, Mexico, 2008, 998-1008.

8. Marwala T., Mahola U., Nelwamondo F.V., Hidden Markov Models and Gaussian Mixture Models for Bearing Fault Detection Using Fractals, Proc. International Joint Conference on Neural Networks, July 16-21, 2006, Vancouver, Canada, 3237-3242.

9. Engelbrecht A.P., Computational Intelligence: An Introduction, John Wiley \& Sons, 2007.

10. Khomfoi S., Tolbert L.M., Fault diagnosis system for a multilevel inverter using a neural network, Proc. 31st Annual Conference of IEEE Industrial Electronics Society, Raleigh, NC, USA, 6-10 Nov., 2005.
11. Sahin S., Becerikli Y., Yazici S., Neural Network Implementation in Hardware Using FPGAs, "LNCS", 4234, ICONIP 2006, Part III, 2006, 1105-1112.

12. Maki Y. Loparo K.A., A Neural-Network Approach to Fault Detection and Diagnosis in Industrial Processes, "IEEE Trans. Control Systems Techn.", Vol. 5, No. 6, Nov 1997, 529-541.

13. Ahmed R.M., El Sayed M.A., Gadsden S.A., Habibi S.R., Fault Detection of an Engine Using a Neural Network Trained by the Smooth Variable Structure Filter, Proc. IEEE Int. Conf. Control Applications (CCA), Denver, CO, USA. September 28-30, 2011, 1190-1196.

14. Bernieri A., Betta G., Pietrosanto A., Sanson C., A Neural Network Approach to Instrument Fault Detection and Isolation, "IEEE Trans. Instr. Meas.", Vol. 44, No. 3, 1995, 747-750.

15. Yang M.-S., Yang J.-H., On Parameter Estimation of Control Chart Patterns Using RBF Neural Network, 4th IEEE Conference on Industrial Electronics and Applications, ICIEA, 25-27 May 2009, Xi'an, China, 1498-1502.

16. Cui L., Wang C., Yang B., Application of RBF Neural Network Improved by PSO Algorithm in Fault Diagnosis, "Journal of Theoretical and Applied Information Technology", Vol. 46, No. 1, 2012, 268-273.

17. Połok B., Bilski P., Optimization of the neural RBF classifier for the diagnostics of electronic circuit, 15th IMEKO TC10 Workshop, 6-7 July, 2017, Budapest, Hungary, 121-126.

18. Drewnik M., Pasternak-Winiarski Z., SVM Kernel Configuration and Optimization for the Handwritten Digit Recognition, Proc. CISIM 2017, 16-18 June 2017, Białystok, Poland, $87-98$.

19. B. Long M. Li, H. Wang, S. Tian, Diagnostics of Analog Circuits Based on LS-SVM Using Time-Domain Features, "Circuits, Systems, and Signal Processing", Dec. 2013, Vol. 32, No. 6, 2683-2706.

20. Kurek J., Osowski S., Support vector machine for fault diagnosis of the broken rotor bars of squirrel-cage induction motor, "Neural Computing and Applications", Vol. 19, Iss. 4, 2010, 557-564, DOI: 10.1007/s00521-009-0316-5

21. Deák K., Kocsis I., Vámosi A., Keviczki Z., Failure Diagnostics with SVM in Machine Maintenance Engineering, "Annals of the Oradea University", No. 1, 2014, 19-24.

22. Bilski P., Automated selection of kernel parameters in diagnostics of analog systems, "Przegląd Elektrotechniczny", No. 5, 2011, 9-13.

23. Dong M., Cheang T., Chan S., On-Line Fast Motor Fault Diagnostics Based on Fuzzy Neural Networks, "Tsinghua Science and Technology", Vol. 14, No. 2, 2009, 225-233.

24. Calado J.M.F., Sa da Costa J.M.G., A Hierarchical Fuzzy Neural Network Approach for Multiple Fault Diagnosis, UKACC International Conference on CONTROL '98, 1-4 September 1998, 1498-1503.

25. Bilski P., Ambiguity groups detection in analog systems diagnostics using Self-Organizing Maps, Proc. IMEKO TC10 Workshop, June 27-28 2016, Milan, Italy, 294-299.

26. Bilski P., Unsupervised learning-based hierarchical diagnostics of analog circuits, 15th IMEKO TC10 Workshop, 6-7 July, 2017, Budapest, Hungary, 99-104.

27. Mirea L., Ron J. Patto, Recurrent Wavelet Neural Networks Applied to Fault Diagnosis, 16th Mediterranean Conference on Control and Automation Congress Centre, Ajaccio, France June 25-27, 2008, 1774-1779.

28. Xuhong W., Yigang H., Diagonal Recurrent Neural Network Based On-line Stator Winding Turn Fault Detection for Induction Motors, Proc. Eighth International Conference on Electrical Machines and Systems, 27-29 Sept. 2005, Nanjing, China, 2266-2269. 
29. Xu X., Chen R., Recurrent Neural Network Based On-line Fault Diagnosis Approach for Power Electronic Devices, Third International Conference on Natural Computation (ICNC 2007).

30. Patan K., Obuchowicz A., Korbicz J., Cascade network of dynamic neurons in fault detection systems, European Control Conference (ECC), 1999, 4232-4237.

31. Huang Y.-C., Yani H.-T., Huang C.-L., A New Intelligent Hierarchical Fault Diagnosis System, IEEE Transactions on Power Systems, Vol. 12, No. 1, 1997, 349-356.

32. Dai H., He J., A Novel Fault Diagnosis Method for Rolling Element Bearings Using Kernel Independent Component Analysis and Genetic Algorithm Optimized RBF Network, "Research Journal of Applied Sciences, Engineering and Technology", Vol. 6, No. 5, 2013, 895-899.
33. LeCun Y., Denker J., Solla S., Optimal brain damage, Advances in NIPS2, Morgan Kaufman, San Mateo, 1900, 598-605.

34. Bilski P., Mazurek P., Wagner J., Application of $k$ Nearest Neighbors Approach to the Fall Detection of Elderly People Using Depth-Based Sensors, Proc. IDAACS 2015 Conference, 24-26 Sept. 2015, Warsaw, Poland, 733-739.

35. Bilski A., Wojciechowski J., Automatic parametric fault detection in complex analog systems based on a method of minimum node selection, "Int. J. Appl. Math. Comput. Sci.", Vol. 26, No. 3, 2016, 655-668, DOI: 10.1515/amcs-2016-0045.

36. Korbicz J., Kościelny J.M., Kowalczuk Z., Cholewa W., Fault Diagnosis. Models. Artificial Intelligence. Applications, Springer Verlag, 2004.

37. Bartyś M., Chosen Issues of Fault Isolation. Theory, Practice and Applications, PWN, Warszawa 2014.

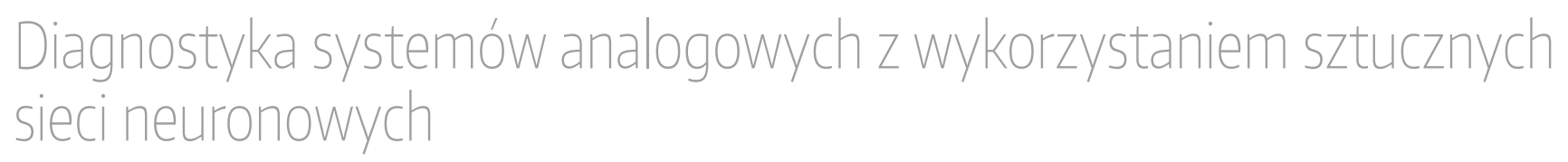

Streszczenie: W artykule przedstawiono zastosowania sztucznych sieci neuronowych w diagnostyce systemów analogowych. Opisano główne cele diagnostyki oraz problemy spotykane obecnie podczas detekcji i lokalizacji uszkodzeń. Wprowadzono ogólną strukturę systemu diagnostycznego opartego na metodach sztucznej inteligencji. Przedstawiono różne metody inteligentne, które mogą zostać zastosowane w systemie działającym w trybie on-line. Następnie omówiono ogólną architekturę sztucznej sieci neuronowej oraz jej cechy szczególnie istotne z punktu widzenia detekcji i lokalizacji uszkodzeń. Specyficzne architektury sieci wraz z ich zastosowaniami diagnostycznymi przedstawiono w szczegółach. Na przykładzie filtru dolnoprzepustowego 5. rzędu przedstawiono działanie metody diagnostycznej wykorzystującej sieć neuronową typu RBF. Omówiono możliwości i ograniczenia stosowalności sztucznych sieci neuronowych jako narzędzia diagnostycznego.

\section{Piotr Bilski, PhD, DSc \\ pbilski@ire.pw.edu.pl}

He was born in 1977 in Olsztyn, Poland. He graduated from Warsaw University of Technology, Institute of Radioelectronics, obtaining MSc degree in 2001 (with honors), PhD degree in 2006 (with honors) and DSc degree in 2014 in computer science. Currently he is an Associate Professor in the Institute of Radioelectronics and Multimedia Technologies, Warsaw University of Technology.

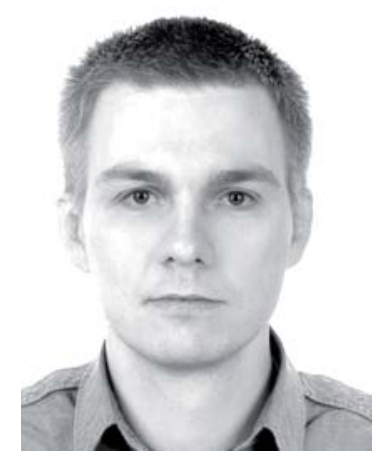
His scientific interests include diagnostics of analog systems, design and analysis of virtual instrumentation, application of artificial intelligence and machine learning methods to the acoustics and environmental sciences. He is the member of IEEE, IMEKO TC10 and POLSPAR and reviewer for such journals like Measurement, IEEE Transactions on Instrumentation and Measurement, and Expert Systems with Applications. His professional record includes 1 book, 53 journal articles (19 in journals from the JCR list), 67 conference papers, and 7 book chapters. 